\title{
SAR Evaluation of Wireless Antenna on Implanted Cardiac Pacemaker
}

\author{
Stanislav Kovar ${ }^{1)}$, Ivan Spano ${ }^{2)}$, Gianluca Gatto ${ }^{2)}$, Jan Valouch ${ }^{1)}$ and Milan Adamek ${ }^{1)}$ \\ 1) Tomas Bata University in Zlín, Faculty of Applied Informatics, Nad Stránémi 4511, 76005 Zlín, Czech Republic \\ 2) Università degli Studi di Cagliari, Via Università, 40, 09124 Cagliari, Italy
}

\begin{abstract}
For many people, pacemaker represents something scary because it is linked with heart problems. However, it is not the main purpose of this paper, the object of the article is technical side of pacemakers especially their immunity against the external influence of electromagnetic fields. Authors focus the attention on the impact of antennas for Wi-Fi signal on a pacemaker.
\end{abstract}

Index Terms-Pacemaker, SAR, half-wave antenna, CST Studio Suite

\section{INTRODUCTION}

Pacemakers have become an object of interest of many scientists because it affects human life. The pacemaker may be described as a device that is used to help a people with heart rhythm disturbances having a character of cardiac arrhythmia such as bradycardia. The pacemaker is possible to imagine like a small device about the size of a few centimeters which contains a lead wire terminated by an electrode. The device monitors the current state of the heart and in the case of need, it sends electric discharge through the electrode into the heart muscle.

Nowadays, great attention is devoted to the concept called electromagnetic compatibility (EMC). It is logical because EMC relates to all electric and electronic equipment whose activities can affect other devices in the environment and simultaneously be affected by electromagnetic radiation from these devices. For purpose of this paper, only one part of EMC is important, namely electromagnetic susceptibility (EMS). This area of EMC is defined as the immunity of component against all sources of electromagnetic interference (EMI).

This study is based on the publication [1], which is interesting and very inspiring. This publication described an impact of mobile radio terminal on the pacemaker. Concurrently, experiment utilizes the findings in the publication [2] dealing with simple half-wave dipole antenna for wireless application. Both articles are combined into new experiment focusing on the determination of SAR distribution caused by new wireless technology on the human body and pacemaker.

Currently, several research papers are dedicated to the issue of electromagnetic radiation affecting pacemakers. However, little amount of them is focused on antennas operating in the frequency of $5 \mathrm{GHz}$. Hence, the idea was born to create a publication that provides information about it. The main purpose of the paper is to evaluate SAR distribution acting on pacemakers.

\section{SPECIFIC ABSORPTION RATE}

Specific absorption rate or SAR is possible to describe as a time derivative of incremental energy absorbed by dissipated in an incremental mass contained in a volume of a given density. [3]

$$
S A R=\frac{d}{d t}\left(\frac{d W}{d m}\right)=\frac{d}{d t}\left(\frac{d W}{\rho d V}\right)
$$

The SAR values may be also calculated according to the following formula. It is related to electric fields at a point. [3]

Where:

$$
S A R=\frac{\sigma}{\rho} \cdot E^{2}\left[\frac{W}{k g}\right]
$$

$\sigma$ - conductivity of the tissue $[\mathrm{S} / \mathrm{m}]$,

$\rho-$ mass density of the tissue $\left[\mathrm{kg} / \mathrm{m}^{3}\right]$,

E - RMS electric field strength $[\mathrm{V} / \mathrm{m}]$.

SAR limits for Europe are specified in European Specification 59005 from 1998 and refer to the knowledge

Table 1. SAR limits for Europe [3]
\begin{tabular}{|c|c|c|c|}
\hline $\begin{array}{c}\text { Whole } \\
\text { body SAR } \\
{[\mathbf{W} / \mathbf{k g}]}\end{array}$ & $\begin{array}{c}\text { Spatial } \\
\text { peak SAR } \\
{[\mathbf{W} / \mathbf{~ k g}]}\end{array}$ & $\begin{array}{c}\text { Averaging } \\
\text { time [min] }\end{array}$ & $\begin{array}{c}\text { Averaging } \\
\text { mass [g] }\end{array}$ \\
\hline 0.08 & 2 & 6 & 10 \\
\hline
\end{tabular}


cited in ICNIRP Guidelines. Some of them are shown in Table 1. [4]

\section{ANTENNA MODEL}

As mentioned above, the antenna selected for this experiment is derived from the publication [2] because it meets requirements of the author for the wireless antenna. The wire antenna has commonly used the type of antenna for transferring of Wi-Fi signal and there exists a high risk of contact between it and a person using implanted cardiac pacemaker.

Antenna was created using the simulation tool CST

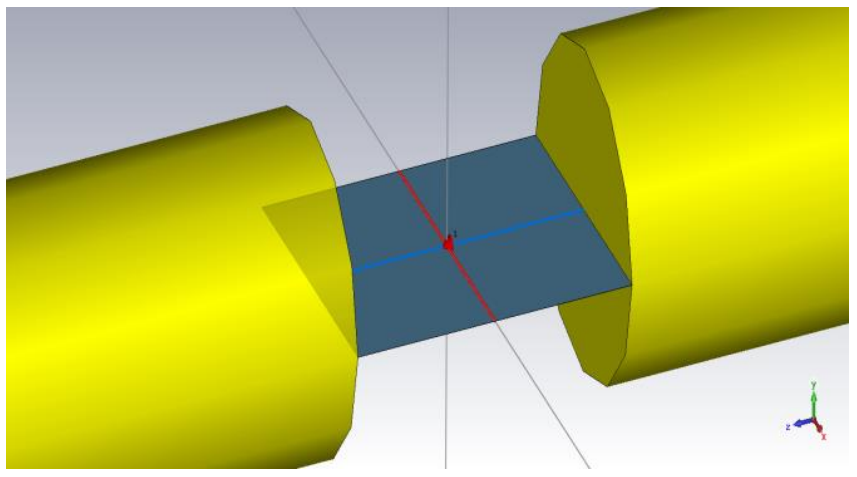

Fig. 1. Half-Wave Dipole Antenna

Microwave according to the information specified in the original paper [2]. All parameters of the antenna are possible to find in Table 2 . These values were checked by authors to meet the requirements of the experiment; however, all calculations are only described in original publication because they are not the purpose of this article. Conversely, the important knowledge is a choice of material, which is used for the wire antenna. In this case, it is copper (annealed). As can be seen in Fig. 1, a discrete face port with the impedance of $73 \mathrm{Ohms}$ is located among dipoles.

Table 2. Parameters of the Antenna [2]

\begin{tabular}{|c|c|c|}
\hline Parameter & Value & Unit \\
\hline Frequency & 5 & $\mathrm{GHz}$ \\
\hline Wavelength & 60 & $\mathrm{~mm}$ \\
\hline Impedance & 73 & $\Omega$ \\
\hline Length of antenna & 28.6 & $\mathrm{~mm}$ \\
\hline Radius & 0.06 & $\mathrm{~mm}$ \\
\hline Gap between dipoles & 0.143 & $\mathrm{~mm}$ \\
\hline
\end{tabular}

\section{HUMAN TORSO MODEL WITH PACEMAKER}

As an inspiration for the elaboration of this part, the authors used the findings listed in the publications [1] and [5]. There is described a human torso and pacemaker which represents the ideal model for simulation. The pacemaker

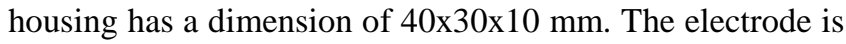
represented by the cube with sides of $6 \mathrm{~mm}$. Both parts are connected by the wire with a diameter of $2 \mathrm{~mm}$ which is composed of a layer of lead, and the insulation layer. A feeding point has a dimension of $4 \times 1 \times 1.6 \mathrm{~mm}$ and it joins radiation element to pacemaker housing with a dimension of
$32.4 \times 23.2 \times 0.5$
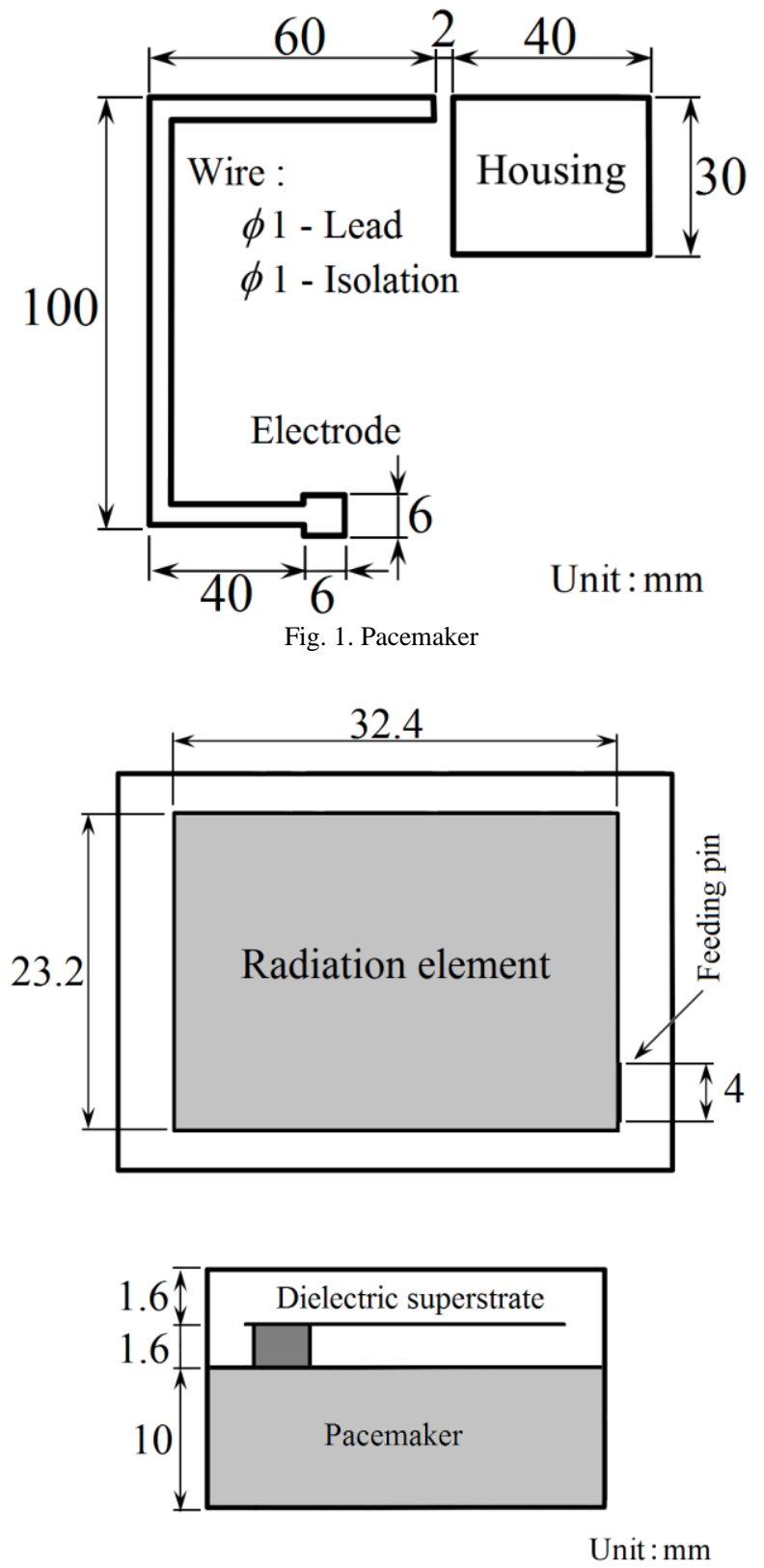

Fig. 3. Pacemaker [1]

The pacemaker was placed into a human torso which has a dimension of 290x450x190 mm. The torso is designed to be like a human body because it contains layers of skin, fat and muscle. The dimensions of these layers were taken from publication [1] and precise parameters are reported in Table 3 . The pacemaker is located in the layer of muscle and the distance approximately $9 \mathrm{~mm}$ from the surface of the torso.

Table 3. Parameters of the Torso [1]
\begin{tabular}{|c|c|c|c|}
\hline Width & $\begin{array}{c}\text { Wength } \\
{[\mathbf{m m}]}\end{array}$ & $\begin{array}{c}\text { Thickness } \\
{[\mathbf{m m}]}\end{array}$ & $\begin{array}{c}\text { [mm] } \\
\text { Skin }\end{array}$ \\
\hline Fat & 290 & 450 & 190 \\
\hline Muscle & 274 & 446 & 186 \\
\hline
\end{tabular}




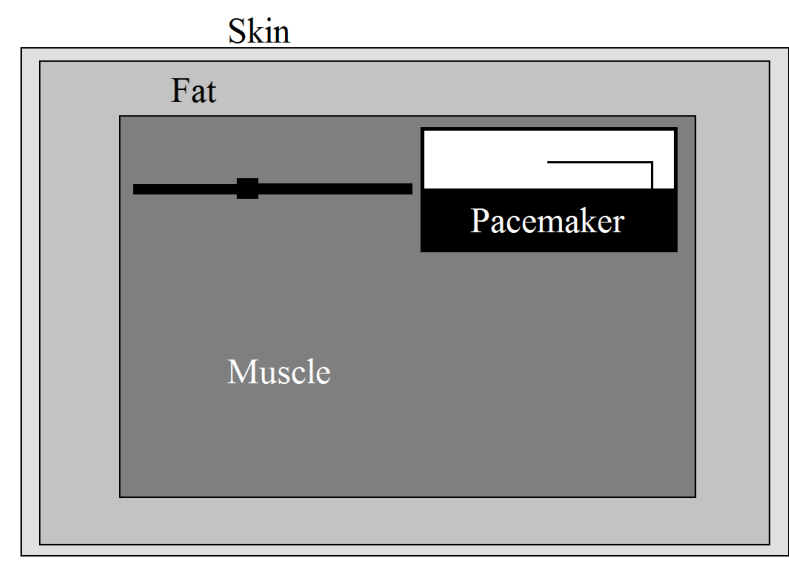

Fig. 2. Layers of Torso [1]

\section{Calculated Results}

In the follow-up phase of the study, there are described results acquired during the simulation. In the first step, it is necessary to describe the antenna polarisation and the distance between it and the surface of the human torso or the pacemaker. These findings are possible to see in Fig. 3 and 4.

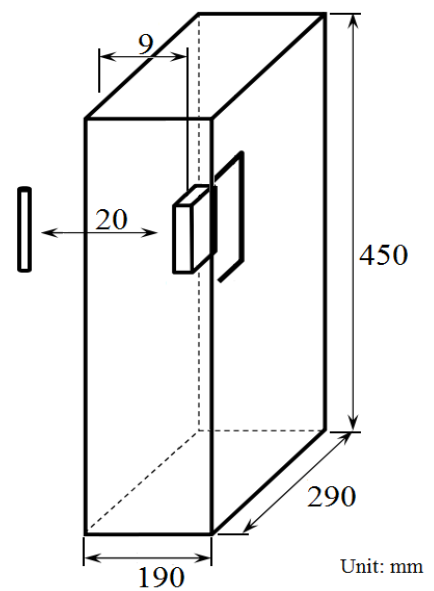

Fig. 3. Antenna direction: $\mathrm{z}$

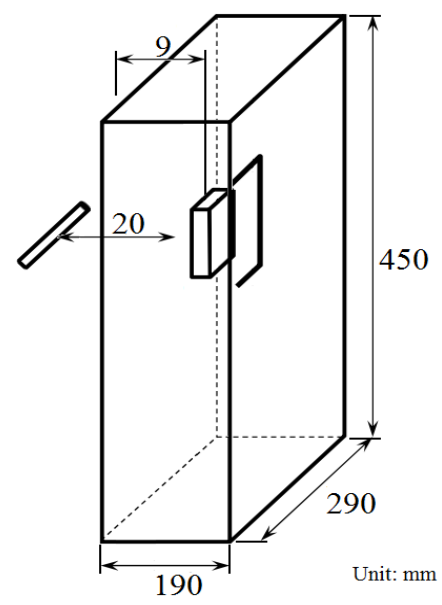

Fig. 4. Antenna direction: $\mathrm{x}$
Time Domain Solver was used to calculate SAR limits because it allows obtaining SAR values in each position. According to the standards, a maximum of mass averaged SAR for Europe is $2.0 \mathrm{~W} / \mathrm{kg}$ averaged over $10 \mathrm{~g}$ of tissue. Therefore, the authors focused this experiment on the calculation of SAR values for $10 \mathrm{~g}$ of tissue. A position of dipole antenna was changed due to acquiring maximum SAR limits. As can be seen in Fig. 3 and 4, there was chosen only two directions in which the limits reach interesting values.

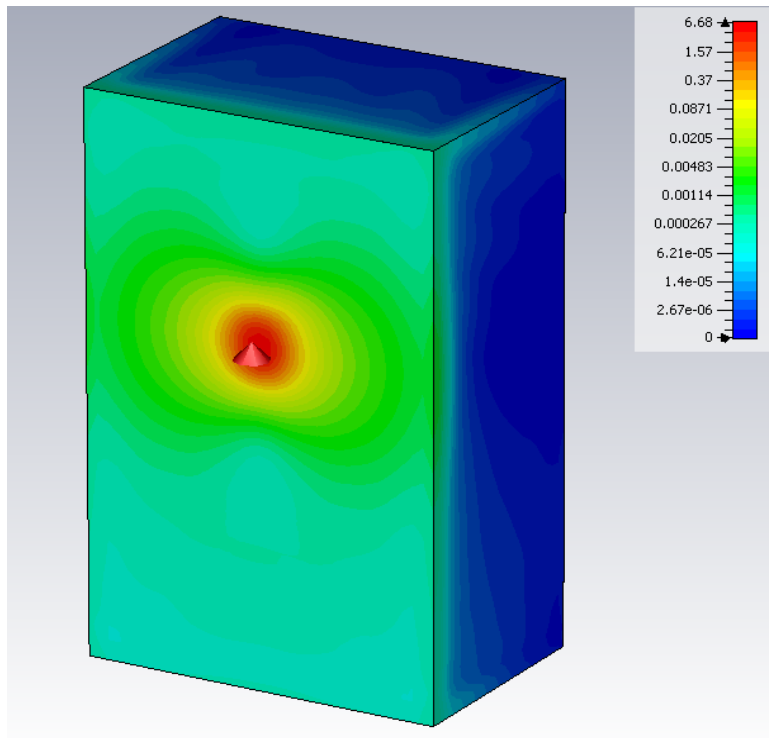

Fig. 5. SAR limits for z-direction.

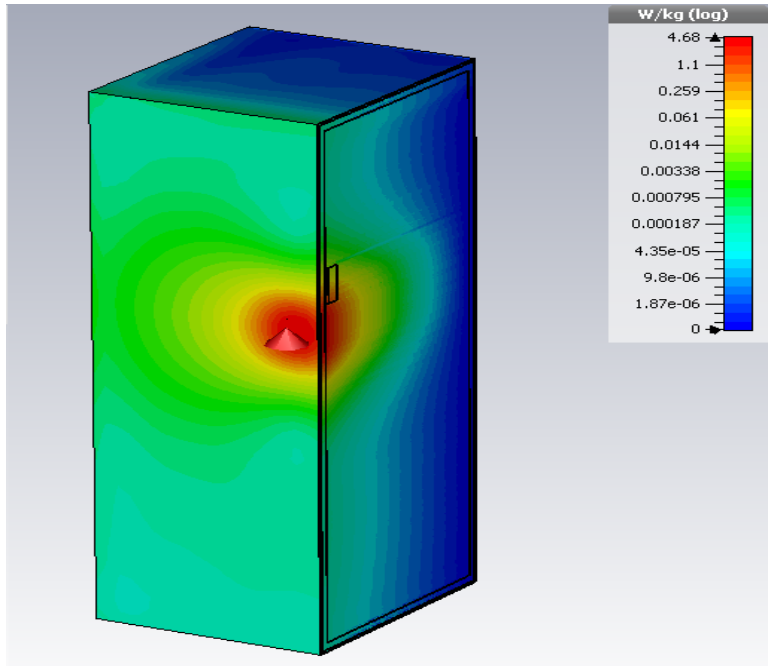

Fig. 6. SAR limits for z-direction (Cutting plane).

Interesting for the reader may be the Fig. 5 and 7, there is possible to compare SAR values in different antenna directions. In both situations, there is an opportunity to see the cutting plane which transfers 3D field on a $2 \mathrm{D}$ plane. It is suitable in terms of monitoring the distribution of the radiation level hitting the pacemaker from a different perspective. 


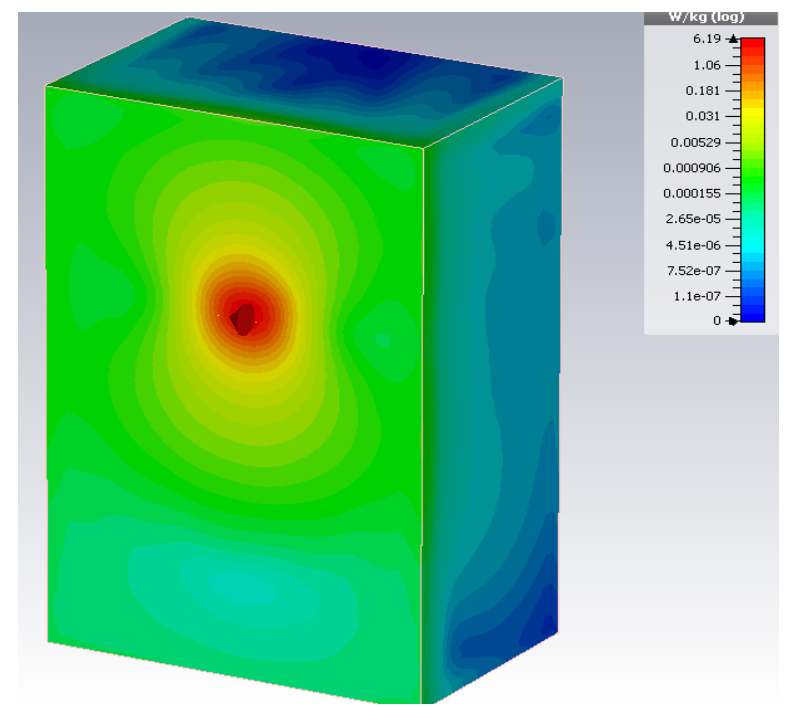

Fig. 7. SAR limits for $\mathrm{x}$-direction.

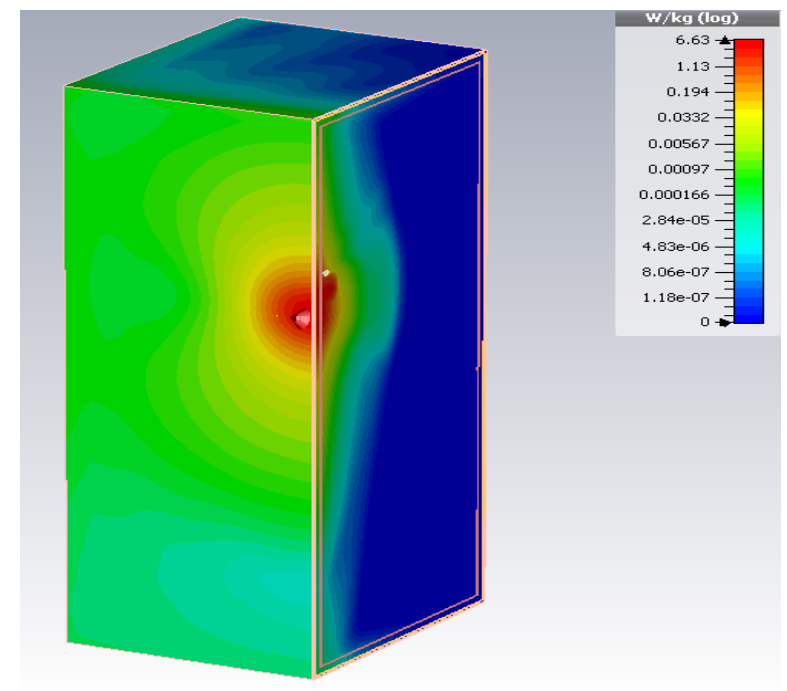

Fig. 8. SAR limits for $\mathrm{x}$-direction (Cutting plane).

\section{CONCLUSION}

This article summarizes the issue of electromagnetic fields affecting the Implanted Cardiac Pacemakers. According to the results, electromagnetic radiation generated by the dipole antenna is the highest on the surface of the torso. In the case of the pacemaker, there is especially influenced the radiation element, lead and electrode which are closest to the torso surface. SAR values calculated by CST Studio are higher that those listed in Table 1. Despite the results, it is necessary to take into account the fact that the level of electromagnetic radiation is proportional to the distance from the antenna to the torso. The purpose of this paper was to expand current findings of evaluations on SAR around implanted cardiac pacemaker caused by wi-fi antennas. It is important to note that there are not many similar publications for wireless antennas in frequency band $5 \mathrm{GHz}$ and therein lies the uniqueness of contribution.

\section{ACKNOWLEDGMENT}

The work was funded with the support of the Internal Grant Agency of Tomas Bata University under the project No. IGA/CebiaTech/2016/005, and support of research project No. LO1303 (MSMT-7778/2014) by the Ministry of Education, Youth and Sports of the Czech Republic within the National Sustainability Programme and also by the European Regional Development Fund under the project CEBIA-Tech No. CZ.1.05/2.1.00/03.0089.

\section{REFERENCES}

[1] TAKAHASHI, Masaharu a Koichi ITO. Implantable Health Care System Paradigm. Handbook of Biomedical Telemetry [online]. Hoboken, NJ, USA: John Wiley \& Sons, Inc, 2014, s. 549 [cit. 2016 09-18]. DOI: 10.1002/9781118893715.ch19. ISBN 9781118893715. Available at: http://doi.wiley.com/10.1002/9781118893715.ch19

[2] TAREQ, Mohammad, Dewan ASHRAFUL ALAM, Mazidul ISLAM a Razin AHMED. Simple Half-Wave Dipole Antenna Analysis for Wireless Applications by CST Microwave Studio. International Journal of Computer Applications [online]. 2014, 94(7), 21-23 [cit. 2016-10-19]. DOI: 10.5120/16355-5734. ISSN 09758887. Available at: http://research.ijcaonline.org/volume94/number7/pxc3895734.pdf

[3] SEABURY, David. An update on SAR standards and the basic requirements for SAR assessment. Available at: www.etslindgren.com/pdf/sar_lo.pdf.

[4] KODALI, Santhisri, Alex BAHER a Dipan SHAH. Safety of MRI s in Patients with Pacemakers and Defibrillators. Methodist DeBakey Cardiovascular Journal [online]. 2013, 9(3), 137-141 [cit. 2016-1107]. DOI: $10.14797 / \mathrm{mdcj}-9-3-137$. ISSN 1947-6094. Available at: http://journal.houstonmethodist.org/doi/abs/10.14797/mdcj-9-3-137

[5] SAITO, Kazuyuki, WATANABE, Ryohei, ENDO, Yuta, WATANABE, Soichi, TAKAHASHI, Masaharu, and Koichi ITO, "Evaluations on SAR around Implanted Cardiac Pacemaker by Mobile Radio Terminal," Proc. 5th European Conf. on Antennas and Propagation (EuCAP), pp.2778-2780, Rome, Italy, Apr. 2011.

[6] ENDO, Yuta, Kazuyuki SAITO, Soichi WATANABE, Masaharu TAKAHASHI a Koichi ITO. Experimental Evaluation of SAR around an Implanted Cardiac Pacemaker Caused by Mobile Radio Terminal.IEICE Transactions on Communications [online]. 2012, E95.B(6), 2129-2132 [cit. 2016-10-19]. DOI: 10.1587/transcom.E95.B.2129. ISSN 0916-8516. Avalilable at: http://jlc.jst.go.jp/DN/JST.JSTAGE/transcom/E95.B.2129?lang=en\& from $=$ CrossRef $\&$ type $=$ abstrac 